\title{
DESIGN AND IMPLEMENTATION OF A SMART HOME AUTOMATION SYSTEM BASED ON GLOBAL SYSTEM FOR MOBILE COMMUNICATIONS
}

\author{
Mohanad Ghazi Khamees ${ }^{1 *}$, Omar Al-Mukhtar Tawfeeq ${ }^{2}$, Qusay Shihab Hamad ${ }^{3}$ \\ ${ }^{1}$ Al-Farabi University College, Iraq \\ ${ }^{2}$ Al-Mamoon University College, Iraq \\ ${ }^{3}$ University of Information Technology and Communication, Iraq
}

Recently, there has been an increasing advancement in the communications technology, and due to the increment in using the cellphone applications in the diverse aspects of life, it became possible to automate home appliances, which is the desired goal from residences worldwide, since that provides lots of comfort by knowing that their appliances are working in their highest efficiency whenever it is required without their knowledge, and it also allows them to control the devices when they are away from home, including turning them on or off whenever required.

The design and implementation of this system is carried out by using the Global System of Mobile communications (GSM) technique to control the home appliances - In this work, an electric fan is used, and a sounding buzzer is used as well - and that is through the utilization of Short Message Services (SMS). Besides that, an Arduino board has been integrated with a number of sensors such as a motion sensor, a temperature sensor, and a screen for displaying required information to the user which indicates whatever the system is doing, where this data includes the state of appliances, where the Arduino board can control the home appliances through the relay board that accepts low power signals, and based upon them, it activates high power devices.

Key words: GSM; Motion Sensor; Temperature Sensor; Arduino; Home Automation

\section{INTRODUCTION}

The Smart Home Automation concept has existed from many years, with improved features in each year. In 1975 , the first home automation network technology was developed,where it relied on acommunication protocol for controlling electronic appliances.

Itbasically uses electrical signals transmission for signaling and control, where the signals involve radio frequency (RF) of both digital and analogdata such that controlling the appliances remains activein the most efficient way. Home automation is the residential extension of home devices, and involves the control and automation of lighting, ventilation, air conditioning, and other equipment, and security of these systems as well. [1]

Nowadays, Home automation plays an importantrole in modern lifestyle because of its success in being utilized atdifferent locations with high quality, which will therefore savetime by decreasing human work automatically. Theconventional home system is a group of electric devices that are standalone systems that donot communicate. The improved system is programmable, such as sensorsthat can be remotely controlled. [2]

Homeautomation systems presents and reports the condition of theconnected devices in a simple, user-friendly interface, whichallows the user to interact and control various devices in an easy manner. Some of the major communicationtechnologies used by today's home automation systems include Bluetooth, WiMAX and Wireless
Local Area Network (WLAN),Wireless Fidelity(Wi-Fi),Zigbee, and Global System for Mobile Communication(GSM). [3][4]

Among the cellular communication methods, GSM isfavored for the communication between the building devicesand the user because of its availability, which makesthe system responsive all the time[5][6]. Another advantage of using GSMtechnique in home controlling is itshigh security, which provides ultimatereliability, whereunintended people cannot interfere with the systemto observe theinformation that is being sent or received [7] [8].

\section{RELATED WORKS}

In [1],home automation realization was performedusing Bluetooth for communication, but usingBluetooth provides a very short range, but when using $\mathrm{Wi}-\mathrm{Fi}$, thecost and complexity areincreased to a great extent,whereas in other projects, GSM moduleswere used where the range of the other systems ishigh at low cost.

In [2], the presented design proposed a simple home automation system that was based onSMS technology, and byusing PIC16F887Micro-Controller Unit (MCU) with the addition of GSM. The system was implemented and checked with greatest number of four devices, andit showedan accuracy of $\geq 98 \%$, where it had a lower accuracy when the number of devices increased.

In [3],a home automation system approach was given based on Bluetoothat two operating frequency bands, 
where the first was ranging from 2400 MHzto 2483.5 $\mathrm{MHz}$, and the other was ranging from $2402 \mathrm{MHz}$ to 2480 $\mathrm{MHz}$. The coverage distance of Bluetooth usually ranges from 0 to 100 meters.

In [4],the authors suggestion was based on voice recognition commands, and it used low-power RF ZigBee wireless communication boards thathave an inexpensive price compared to other technologies. The system hadbeen verified, wherethe verification tests included a speech recognizing test, and a ZigBee communication test. The tests involved a mix of 70 commands, where 80.05 percent of these commands were recognized without an error.

In [5], a GSM based Device Control System wasimplemented by using the (App Inventor) program that is developed at Google Laboratories by a team led by a Massachusetts Institute of Technology(MIT) programmer called Hal Abelson, where the program is meant forAndroid smart phones that hasa vast market, which is most beneficial for the people since Android is the most commonly used Operating System (OS) globally.

\section{SYSTEM REALIZATION}

This work implements Short Message Service (SMS) based control system for monitoring home appliances using an Arduino UNO board,which features an ATmega328P MCU. Themicrocontroller acts as the bridge between theYixin GSM board -that features SIM800 module, where this board can also perform General Packet Radio Service (GPRS) communication-and sensors and actuators of the home automation system. The Yixin board contains the Subscriber Identity Module (SIM) card that the user can communicate with in order to utilize the functions of the system.

The GSM based home automation system consists of three main parts: The Mobile Station (MS), the GSM Base Transceiver Station (BTS) and the home automa- tion controller, where these three partsare shown in Figure 1 . The MS is basically a mobile phone that can operate on a network that utilizes SMS, the BTS is basically a piece of equipment that facilitates wirelesscommunication among multiple MS's, or between one BTS and another in order to support long range calls.

Nowadays, both MS and BTS are implemented and easily utilized in our community, so this research will focus mainly on the design and implementation of the home automation controller only, which consists of an Arduino UNO,Yixin GSM/GPRS module, and different sensors and peripherals like motion sensor, temperature sensor, relay module to control high current home appliances.

\section{Arduino UNO board}

Arduino Uno is a board that contains the ATmega328P, which isan 8-bit Atmel Reduced Instruction Set Computer (RISC) thatincludes $32 \mathrm{~KB}$ of flash memory that can write data or read it, 2 KB SRAM, 1 KB EEPROM [9]. It has 14 digital $\mathrm{I} / \mathrm{O}$ pins of which 6 can generatea Pulse Width Modulation (PWM) signal, 6 analog inputs, a 16 $\mathrm{MHz}$ oscillator, a Universal Serial Bus(USB) connection, a power connector, a reset on board button and In-Circuit Serial Programming(ICSP) $3 \times 2$ connection socket.

To interact with all these input/output pins, one can simply use the Arduino Integrated Development Environment (IDE), which is a program written in Java. Arduino IDE contains a text editor for writing code, a message area for showing errors and debugging, a toolbar with buttons for common functions, and a series of menus [10].

\section{Yixin GSM/GPRS Board}

This board contains the SIM800 module, which is a complete Quad-band GSM/GPRS solution in a Surface Mount Technology (SMT) platform, which can be em-
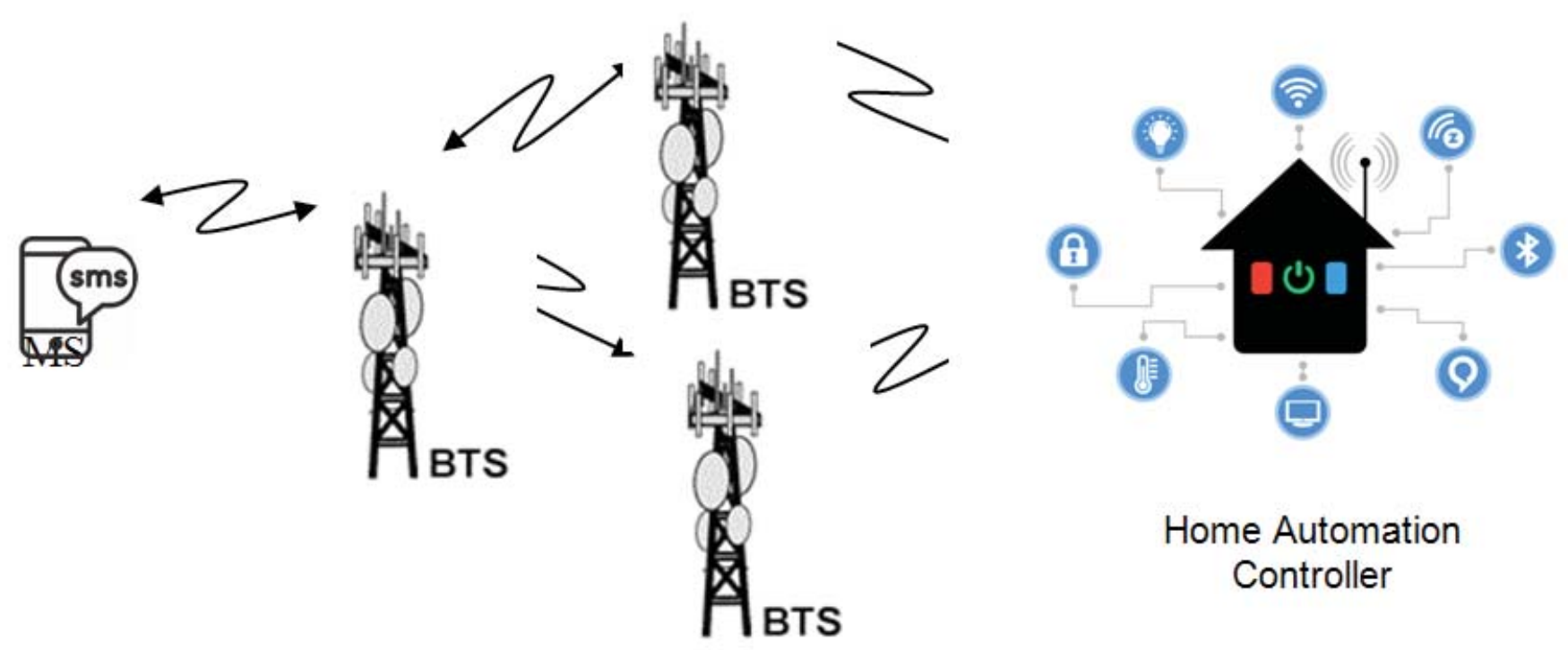

Figure 1: Simplified GSM based home automation 
bedded in the customer applications. SIM800 support $850 / 900 / 1800 / 1900 \mathrm{MHz}$ bands.It can establish Voice transmission, SMS communication and data transfervia Attention (AT) commands with low power consumption, it works in a temperature range of : -40 o $\mathrm{C} \sim 850 \mathrm{C}$. It has a tiny size of $24^{*} 24^{*} 3 \mathrm{~mm}$, it can fit into slim and compact boards, it also allows major savings in total cost [11].

\section{Pyroelectric infrared (pir) motion sensor}

PIR sensors are able to sense motion and they are always used to detect whether a human has moved in or out of the sensors range. They are small, inexpensive, consume low-power, easy to use, and donot wear out. For that reason, they are commonly found in appliances and gadgets used in homes or businesses. They are often referred to as PIR, "Pyroelectric Infrared", or "IR motion" sensors.

PIR's are basically made of a pyroelectric sensor (which you can see below as the round metal can with a rectangular crystal in the center), which can detect levels of infrared radiation. It relies on the fact that everything emitslow level radiation, and the hotter something is, the more radiation is emitted, which increases chances of detection [12].

\section{LM35 Precision Centigrade Temperature Sensors}

The LM35 is an Integrated Circuit (IC) based temperaturesensor, whose output signal is linearly proportional to theCentigrade (Celsius) temperature. The LM35 thus has anadvantage over other temperature sensors that operate in ${ }^{\circ}$ Kelvin, as the programmer is not obliged to perform complicated mathematical operationson its output voltage toobtain convenient Centigradereadings. External calibrating and trimming the LM35 is not a must to provide typical accuracies of $\pm 13^{\circ} \mathrm{Cat}$ room temperature and $\pm 3 / 2^{\circ} \mathrm{C}$ over a full -52 to $+145^{\circ} \mathrm{Ctemperature} \mathrm{range.}$ The low impedance and precise calibration of the LM35 makeinterfacing this sensor to read its data in order to control other circuitry verysimple [13].

\section{Relay Module}

A relay is an electrical switch used to terminate or establish a circuit using a low power signal from a microcontroller. It provides complete electrical isolation between microcontroller and controlled circuits. There is a wide variety of relays based on the voltage and current that can be handled.For example, the Relay click board provided by MikroElektronika features two G6D1AASI-5DC power Printed Circuit Board (PCB) relay modules. The click is designed to run on $5 \mathrm{~V}$ power supply only to control various devices with up to $5 \mathrm{~A}, 250 \mathrm{~V}$ AC/30V DC loads. [14]

\section{Other Peripherals for Home Automation}

When it comes to home automation, there is a wide variety of peripherals, some of them are visible like the RG-
BLED, others are audible like the buzzer. Such peripherals are combined with other sensors that are mentioned above to make an alarm system.For example, The RGB LEDis combined with the temperature sensor to indicate the current room temperature, and the buzzer is combined with the motion sensor to produce an alarming tone when a movement is detected within the sensing range of the motion sensor.

\section{THE PROPOSED CIRCUIT}

The circuit implemented in this work consists of 7 parts, which are:The Arduino board, motion sensing unit, temperature sensing unit, motion alarming unit, temperature alarming unit, relay switching unit, and GSM unit as shown below in figure 2 .

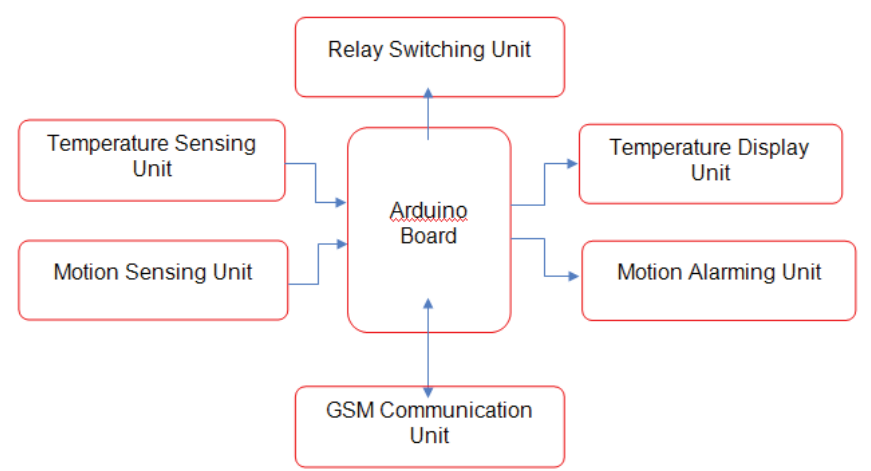

Figure 2: Block diagram of the connected circuit

\section{The Temperature Sensing Unit}

This unit consists of the ( LM35 ) temperature sensor that was described earlier, it sends its data to the Arduino board once each two seconds through the A0 pin of the Arduino as shown in figure 3 , where that analog pin had been used since the readings of this sensor are analog values. The part of the Arduino code that this sensor needs to initialize and sends its data is given next:

const int Temp = A0;

float Value;

float Heat;

...

void $\operatorname{setup}()$

\{

$\cdots$

\}

void loop()

\{

Value = analogRead $($ Temp);

Heat $=$ Value ${ }^{*} 5 / 10.24$;

$\ldots\}$

The three dots ( ... ) in the above code and the following codes indicate that there are other code lines in this part of the Arduino program, but those code lines do not affect the operation of the module currently being explained. 


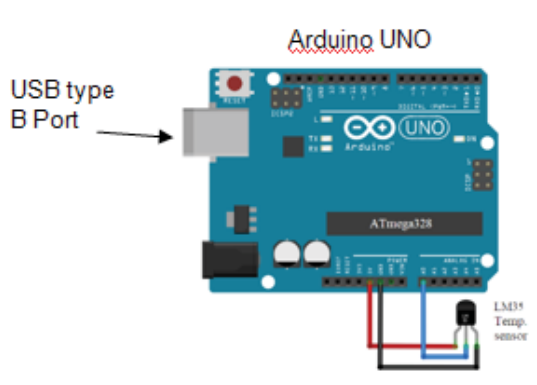

Figure 3: Arduino board with temperature sensor

\section{The Temperature Sensing Unit}

This unit consists of the RGB LED that was mentioned earlier, where the RGB LED receives its signals from the Arduino board through pins \#10, \#11, and \#12, where these digital pins had been used since enabling or disabling one of the three anodes of the RGB LED requires a logic 1 or a logic 0 respectively, where both values are digital. Pin \#10 is used to control the anode of the red color, while pin \#11 is used to control the anode of the blue color, while pin \#12 is used to control the anode of the green color as shown in figure 4, where the relay board shown will be explained later.

In this work, blue light will be emitted when the temperature is low,yellow light will be emitted when the temperature is warm, red light will be emitted when the temperature is hot,while when the temperature is extremely hot, then the RGB LED will blink red light, activate one of the two relays of the relay switching unit, and an SMS will be sent through the GSM communication unit, where bothrelay unit and GSM unit will be explained later.The part of the Arduino code that this unit needs to initialize and receive its data is given next:

int $\mathrm{x}$;

float Heat;

.

void $\operatorname{setup}()$

\{

pinMode(3, OUTPUT);

pinMode(10, OUTPUT);

pinMode(11, OUTPUT);

pinMode(12, OUTPUT);

digitalWrite(3, LOW);

digitalWrite(10, LOW);

digitalWrite(11, LOW);

digitalWrite(12, LOW);

...

\}

void loop()

\{

if $($ Heat $<32)$
\{

digitalWrite(10, LOW);

digitalWrite(11, HIGH);

digitalWrite(12, LOW);

\}

else if $((32<$ Heat $) \& \&($ Heat $<34))$

\{

digitalWrite(10, HIGH);

digitalWrite(11, LOW);

digitalWrite(12, HIGH);

else if $((34<$ Heat $) \& \&($ Heat $<40))$

\{

digitalWrite(10, HIGH);

digitalWrite(11, LOW);

digitalWrite(12, LOW);

\}

else if ( Heat $>40$ )

\{

digitalWrite(11, LOW);

digitalWrite(12, LOW);

digitalWrite(3, HIGH);

// This line enables the relay.

GPRS.printIn("AT+CMGS=|"07123456789|"');

// Change this into your phone number

delay(500);

GPRS.printIn("Temperature too high! The extinguish device is activated!");

GPRS.write( 0x1a );

for $(x=0 ; x<7 ; x++)$

\{

digitalWrite(10, HIGH);

delay(250);

digitalWrite(10, LOW);

delay(250);

\}

delay(1000);

digitalWrite(3, LOW);

/l
\}

$\cdots$

\} 


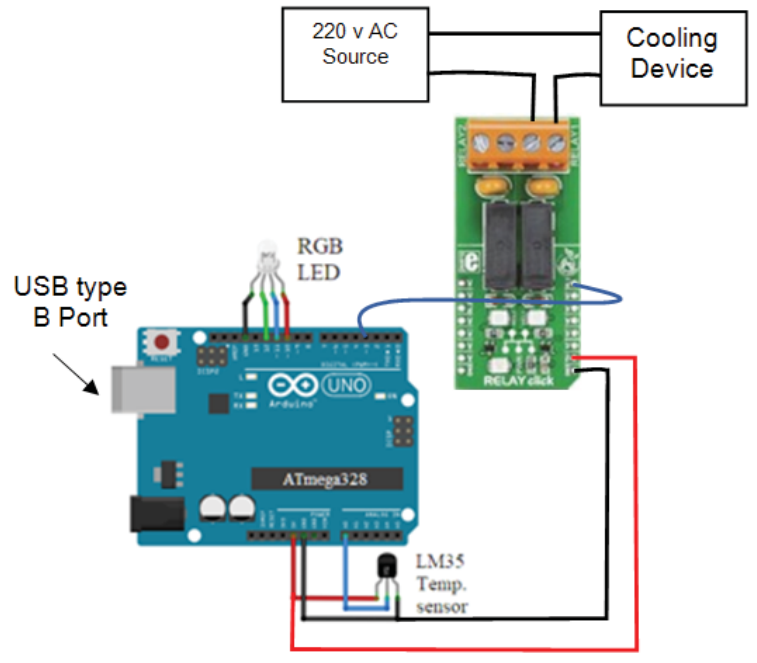

Figure 4: Arduino with relay board and RGB LED

\section{The Motion Sensing Unit}

This unit consists of the ( PIR ) motion sensor that was described earlier, when motion is detected by this sensor, it sends its signals to the Arduino board through pin \#2 as shown in figure 5 , where this digital pin had been used since the readings of this sensor are digital values. The part of the Arduino code that this sensor needs to initialize and sends its data is given next:

\section{boolean Motion;}

$\ldots$

void setup()

\{

...

pinMode(2, INPUT);

...

\}

void loop()

\{

$\ldots$

Motion = digitalRead $(2)$;

if ( Motion == 1 )

\{

...

// The code written here activates the Motion

// Alarming Unit and the GSM Communication

// unit, which will be explained later

$\cdots$

\}

$\cdots$

\}

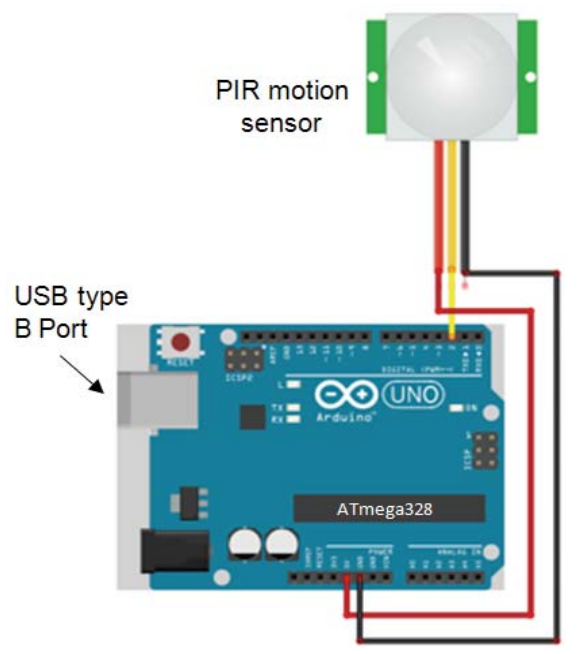

Figure 5: Arduino with motion sensor

\section{The Motion Alarming Unit}

The first part of the motion alarming unit is a sounding part, where it consists of the (Buzz Click) that was described earlier, where the on-board buzzer does not make a sound by default, but it starts beeping whenever a motion is detected. There is a slide switch connected close by the ( Buzz Click ) that controls its operation (Enabling or disabling sound), where the entire circuit could be operated in the silent mode if required.

This part of themotion alarming unit receives its data from the Arduino board through pin \#9 as shown in figure 6 , where this digital pin had been used since it could generate a PWM signal. That is indicated by the $\sim$ sign near the number 9 on the Arduino Uno board. Other than the buzzer, the system will also activate the other relay of the relay switching unit, and it will send an SMS through the GSM communication unit. The part of the Arduino code that this unit needs to initialize and receive its commands is given below:<smiles></smiles>

void setup()

\{

pinMode(4, OUTPUT); pinMode $(9$, OUTPUT);

$\cdots$

\}

void loop()

\{

if $($ Motion $==1)$

\{

digitalWrite(4, HIGH);

GPRS.printIn("AT+CMGS=|"07123456789|"'); // Change this into your phone number 
$\operatorname{delay}(500)$;

GPRS.println("Motion detected! The door lock siren is activated!");

GPRS.write( 0x1a );

for $(x=0 ; x<7 ; x++)$

\{

tone $(9,700,500)$;

delay (250);

tone $(9,0,500)$;

delay(250);

$\ldots$

\}

delay(1000);

digitalWrite(4, LOW);

$\cdots$

\}

...

\}

\section{The GSM Communication Unit}

This unit consists of the (Yixin GSM/GPRS board ) that was described earlier. Its operation is to send an SMS to a specified phone number by the user signaling whenever the motion sensor is triggered, or whenever there is a very high temperature. This unit receives its data and commands from the Arduino board through pin \#0 and pin \#1 as shown in figure 7 and figure 8 , where these digital pins had been used since they could UART communication on the Arduino Uno board. The part of the Arduino code that this unit needs to initialize and perform its operations is given below:

SoftwareSerial GPRS $(0,1)$;

...

void setup()

\{

delay(1000);

GPRS.printIn("AT+CMGF=1");

delay(1000);

$\ldots$

\}

void loop()

\{

// This code part was written earlier

// while explaining the alarming

// units of both temperature and

// motion units.

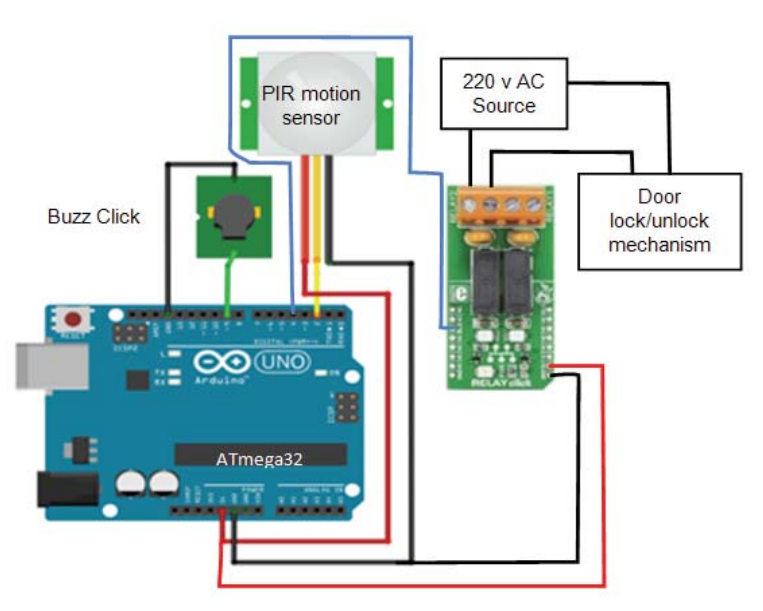

Figure 6: Arduino with motion modules and relay board

\section{The Relay Switching Unit}

This unit consists of the ( Relay Click ) board that was described earlier, where this board carries two relays, one is used when a motion is detected, while the other is used when there is a drastic increase in temperature. This unit receives its commands from the Arduino board through pins \#3 and \#4, where these digital pins had been used since short circuiting or open circuiting one of the two relays requires a logic 1 or a logic 0 respectively, where both values are digital. The initial state of the devices connected to these relays is that both of them are off.The part of the Arduino code that this unit needs to initialize and receive its commands is given below:

...

void setup()

\{

pinMode(3, OUTPUT);

pinMode(4, OUTPUT);

digitalWrite(3, LOW);

digitalWrite(4, LOW);

$\cdots$

\}

void loop()

\{

// This code part was written earlier

// while explaining the alarming

// units of both temperature and

// motion units.

...

\} 

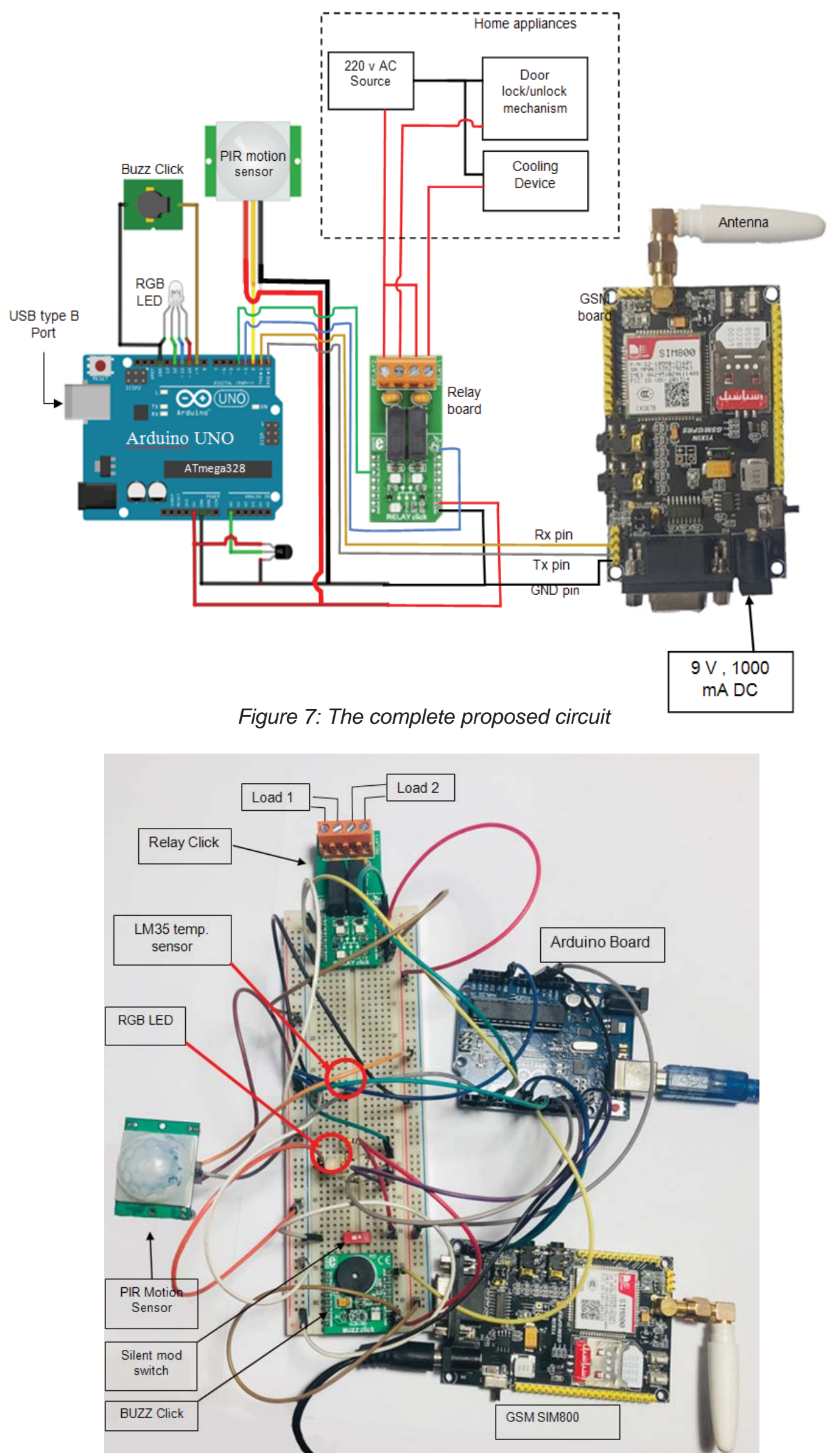

Figure 8: Prototype model for smart home automation 


\section{Flowchart of Operation}

The code for this work was written in Arduino Integrated Development Environment (IDE), where it consists of two parts. In the first part that is shown in figure 8-A, the operations that are performed are listed below:

1 - The input and output Arduino pins are initialized by deciding which of them perform which required task.

2 - The baudrate between the GSM board and the Arduino board are specified for ensuring proper communication.

3 - A repetitive loop begins that starts with testing whether a motion is detected or not.

4 - If a motion is detected, then the buzzer will start making sounds, an SMS will be sent to a specified number as well, and a relay will activate a high-power device.

The previous steps are illustrated in figure 8-A.

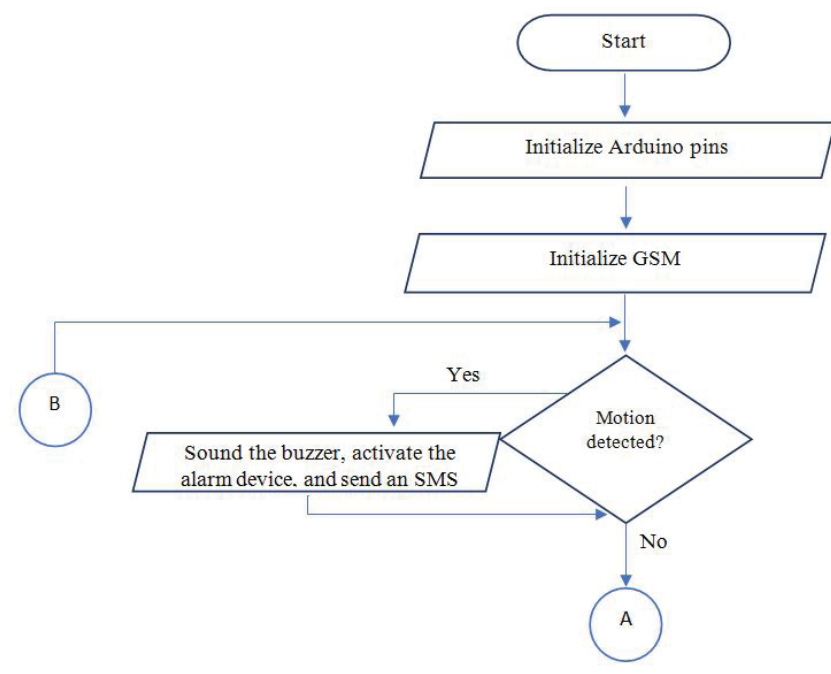

Figure (8-A): first part of the flowchart for the proposed system

For the second part of the flowchart that is shown in figure 8-B, the operations that are performed are listed below:

1 - After the checking for motion detection in previous step, the temperature sensor sends its data to the Arduino, and it gets displayed on the RGB LED.

2 - In case the temperature is too high, then the LED will start turning on and off to alarm nearby people, an SMS will be sent as well, and a cooling device will be activated by the relay.

3 - If the program is terminated afterwards, then the loop starts from the beginning.

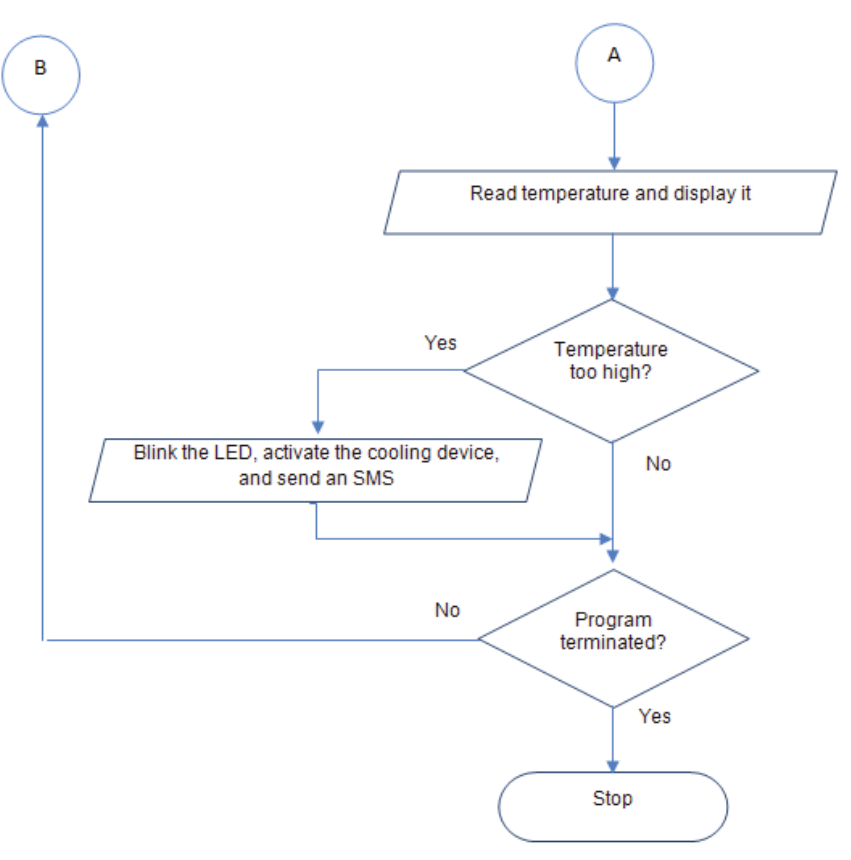

Figure (8-B) Second part of the flowchart for the proposed system

\section{CONCLUSION}

The smart home automation is novel idea with a noble goal, where it aims to reduce the consumption of electrical energy and ease our lives. There are different approaches to achieve the concept of smart home automation, one of them was introduced in this work, where the system used GSM technology to communicate with the owner of the home.

The goal of this work was to design and implement a system that senses whether there is a motion in a room inside a building, and measure the temperature in that room as well, and then turn on or off specific appliances based on those readings. The system also reports to a cellphone through an SMS whenever it is required to do so.

The main advantage of using GSM over other communication technologies is that it is the most reliable technique given that it has the longest range, and not requiring the connection to a WiFi network in order to work.

\section{REFERENCES}

1. Shubham Magar, Varsha Saste, (2017)Smart Home Automation By Gsm Using Android Application. International Conference On Information, Communication \& Embedded Systems (ICICES 2017).

2. Kok Wai Chan, Rozita Teymourzadeh, (2013) Smart GSM based Home Automation System. IEEE Conference on Systems, Process \& Control (ICSPC2013), Kuala Lumpur, Malaysia, 13 - 15 December 2013. 
3. Marimuthu Ramakrishnan, Bala Murugan, (2016) Home automation using bluetooth:a review. ARPN Journal of Engineering and Applied Sciences, VOL. 11, NO. 21, NOVEMBER 2016.

4. S. Benjamin Arul, (2014) Wireless Home Automation System Using Zigbee. International Journal of Scientific \& Engineering Research, Volume 5, Issue 12, December2014.

5. Mahesh N. Jivani, (2014) GSM Based Home Automation System Using App-Inventor for Android Mobile Phone. International Journal of Advanced Research in Electrical, Electronics and Instrumentation Engineering, Vol. 3, Issue 9, September 2014.

6. M. S. Khandare and A. Mahajan, (2013) Mobile Monitoring System for Smart Home. in Proc. 2010 3rd International Conference on Emerging Trends in Engineering and Technology (ICETET), Goa, pp.848 852.

7. G. Gu and G. Peng, (2010) The survey of GSM wireless communication system. in Proc. 2010 International Conference on Computer and Information Application (ICCIA), Tianjin, pp.121 - 124.
8. G. Mingming, Shaoliangshan, Huixiaowei, and Sunqingwei, (2010) The System of Wireless Smart House Based on GSM and ZigBee. in Proc. 2010 International Conference on Intelligent Computation Technology and Automation (ICICTA), Changsha, pp.1017 - 1020 .

9. Microchip Technology Inc. http://www.microchip. com/wwwproducts/ATmega328p

10. Arduino Computing platform "Arduino UNO Rev. 3" https://store.arduino.cc/usa/arduino-uno-rev3

11. SIMCom Wireless Solutions Co., Ltd, Shanghai City, China "SIM800 Introduction"http://simcomm2m.com/ En/module/detail.aspx?id=138

12. Adafruit Industries Ltd, USA, New York, "PIR motion sensor overview" https://learn.adafruit.com/pir-passive-infrared-proximity-motion-sensor?view=all

13. National Semiconductor Corporation, California, USA, "LM35 Precision Centigrade Temperature Sensors", November 2000.

14. MikroElektronika, Belgrade, Serbia, "RELAY click ${ }^{\mathrm{TM}}$ board", https://www.mikroe.com/relay-click 